\title{
A lei das estatais e as diretrizes internacionais: convergências para o estado da arte em integridade, compliance e anticorrupção
}

\author{
MARCos Caldeira ${ }^{1}$ \\ Simone CRISTINA DUfLOth ${ }^{1}$ \\ ${ }^{1}$ Fundação joão Pinheiro (Fjp) / Escola de Governo Professor Paulo NeVes de Carvalho, Belo horizonte - MG, Brasil
}

\begin{abstract}
Resumo
Constitui objetivo deste artigo investigar a convergência das diretrizes de integridade, compliance e anticorrupção introduzidas pela Lei das Estatais, em face das melhores práticas internacionais. Adotam-se, como parâmetro de análise, as Diretrizes em Anticorrupção e Integridade para Empresas de Propriedade Estatal, publicadas pela Organização para a Cooperação e Desenvolvimento Econômico (OCDE). De natureza descritiva, o estudo articula pesquisa bibliográfica e documental e, para a consecução dos objetivos propostos, a técnica adotada envolve a análise comparativa entre o sistema de integridade, compliance e anticorrupção introduzido pela Lei das Estatais e as diretrizes estabelecidas pela OCDE. Como resultado, observou-se que a Lei das Estatais apresenta um grau de convergência considerável em vista das práticas analisadas, tendo introduzido no ordenamento jurídico brasileiro um arranjo normativo de integridade, compliance e anticorrupção que caminha em direção ao que se poderia considerar o 'estado da arte'. No entanto, a despeito de substantivamente aderente às recomendações transnacionais, a lei ainda apresenta limitações e omissões em pelo menos três perspectivas: gestão integrada de riscos; controles internos, ética e compliance; e autonomia das estatais e de seus órgãos decisores. Os resultados da pesquisa sinalizam para uma agenda propositiva de estudos futuros voltados à investigação das alternativas de aperfeiçoamento da Lei das Estatais e do ambiente institucional brasileiro. Também sinaliza para uma agenda de estudos aplicados, devotada a investigar e compreender os desafios da implementação da lei e seus resultados concretos no universo das companhias estatais.
\end{abstract}

Palavras-chave: Integridade. Anticorrupção. Lei das Estatais.

\section{International guidelines and the Brazilian law of state-owned companies: convergence toward cutting-edge integrity, compliance, and anti-corruption practices}

\begin{abstract}
This article aims to investigate the convergence of the integrity, compliance, and anti-corruption guidelines introduced by the Brazilian law of state-owned companies, in view of the best international practices, adopting as an analysis parameter the Anti-Corruption and Integrity Guidelines for State-Owned Companies, published by the Organisation for Economic Co-operation and Development (OECD). This descriptive study used bibliographic and documentary research and adopted a comparative analysis between the integrity, compliance, and anti-corruption system introduced by the Brazilian law of state-owned companies and the guidelines established by the OECD. The practices analyzed suggest a considerable degree of convergence between the Brazilian legislation and the OEDC guidelines. Thus, the Brazilian legal system presents what can be considered a cutting-edge normative arrangement of integrity, compliance, and anti-corruption practices. However, despite substantially adhering to the transnational recommendations, the law still presents gaps and omissions in at least three perspectives: integrated risk management; internal controls, ethics, and compliance; and autonomy of state-owned companies and their decision-making bodies. The research results point to a propositional agenda for future studies, focusing on investigating the alternatives for improving the law of state-owned companies and the Brazilian institutional environment, based on the gaps identified. It also points to an agenda of applied studies devoted to investigating and understanding the challenges of law implementation and its concrete results in the universe of state-owned companies.
\end{abstract}

Keywords: Integrity. Anti-corruption. Law of State-owned Companies.

\section{La ley de responsabilidad de las empresas estatales y las recomendaciones internacionales: convergencias con los últimos avances en integridad, compliance y anticorrupción}

\section{Resumen}

El objetivo de este artículo es investigar la convergencia de las directrices de integridad, cumplimiento y anticorrupción introducidas por la ley de responsabilidad de las empresas estatales, en vista de las mejores prácticas internacionales, adoptando como parámetro de análisis las Directrices Anticorrupción e Integridad para Empresas del Estado, publicadas por la Organización para la Cooperación y el Desarrollo Económicos (OCDE). De naturaleza descriptiva, el estudio articula la investigación bibliográfica y documental. Para lograr los objetivos propuestos, la técnica adoptada implica un análisis comparativo entre el sistema de integridad, cumplimiento y anticorrupción introducido por la ley de responsabilidad de las empresas estatales y las pautas establecidas por la OCDE. Como resultado, se observó que la ley de responsabilidad de las empresas estatales presenta un grado considerable de convergencia en vista de las buenas prácticas analizadas, al haber introducido en el sistema legal brasileño un arreglo normativo de integridad, cumplimiento y anticorrupción, que avanza hacia lo que podría considerarse el último avance. Por otro lado, a pesar de cumplir sustancialmente con las recomendaciones transnacionales, la ley aún presenta brechas y omisiones en al menos tres perspectivas: gestión integrada de riesgos; controles internos, ética y cumplimiento; y autonomía de las empresas estatales y sus órganos de decisión. Los resultados de la investigación apuntan a una agenda propositiva para futuros estudios, con un enfoque en la investigación de alternativas para mejorar la ley de responsabilidad de las empresas estatales y el entorno institucional brasileño. Por otro lado, también apunta a una agenda de estudios aplicados dedicada a investigar y comprender los desafíos de la implementación de la ley y sus resultados concretos en el universo de las empresas estatales.

Palabras clave: Integridad. Anticorrupción. Ley de responsabilidad de las empresas estatales. 


\section{INTRODUÇÃO}

Pauta de destaque no universo corporativo moderno, as discussões em torno da integridade, compliance e anticorrupção ocupam cada vez mais a agenda de conselhos, órgãos reguladores e casas legislativas, inspirando preocupação e debate entre empresas, governos e organismos multilaterais.

No universo das empresas estatais, os recentes e reiterados escândalos de fraude e corrupção, revelados em diversas operações da Polícia Federal e dos Ministérios Públicos ${ }^{1}$ - especialmente a partir da segunda década do século XXI -, expuseram fragilidades e ineficiências nos arranjos de integridade, compliance e anticorrupção até então vigentes, com reflexos diretos na credibilidade e reputação das companhias de propriedade do Estado (Coutinho, Mesquita \& Nasser, 2019).

Nesse contexto notabilizado por imensas repercussões negativas no mercado e na sociedade, aprimorar os mecanismos de integridade e anticorrupção das empresas de propriedade estatal tornou-se indispensável não só para as companhias diretamente expostas pelas operações e investigações, mas para todo o sistema de companhias estatais, bastante representativo para a economia nacional e largamente maculado pelo estigma da corrupção.

Os esforços de resposta à crise tiveram como um de seus efeitos a edição de diplomas legais, tendo como pressuposto a possibilidade de incremento do ordenamento jurídico nacional com novidades capazes de promover avanços na prevenção e no combate à corrupção (Fortini \& Sherman, 2016). Inclui-se neste rol a Lei no 13.303 (2016), conhecida como Lei das Estatais ou Lei de Responsabilidade das Estatais, divisa importante na regulação do regime jurídico das empresas de propriedade do Estado e na modernização de seus arranjos de governança corporativa, integridade e anticorrupção.

Com a edição da Lei das Estatais, as empresas públicas e as sociedades de economias mistas ganharam impulso extra na modernização de seus sistemas de integridade, compliance e anticorrupção. A introdução de diretrizes normativas passou a privilegiar arranjos organizacionais voltados ao controle interno preventivo, focando em uma gestão mais transparente e atenta aos riscos, conduzida pelo compromisso de prestar contas, promover o compliance e assegurar o exercício do controle social (Lei no 13.303, 2016).

Desse modo, torna-se relevante dedicar atenção à compreensão da qualidade dos avanços institucionais introduzidos pela Lei das Estatais, sob a ótica da promoção da integridade e prevenção à corrupção, em um momento de reconstrução do lugar institucional das companhias estatais, seja do ponto de vista da sociedade, que percebe na corrupção um dos principais problemas nacionais (Confederação Nacional da Indústria [CNI], 2018), seja do ponto de vista dos governos, que se articulam em torno de agendas majoritariamente desestatizantes (Lei no 13.334, 2016) - cuja retórica passa pelo uso indevido de algumas empresas estatais como instrumento de malversação de recursos públicos.

Sob essa baliza, constitui objetivo deste artigo investigar a convergência das diretrizes de integridade, compliance e anticorrupção introduzidas pela Lei de Responsabilidade das Estatais em face das melhores práticas internacionais, adotando como parâmetro de análise as Diretrizes em Anticorrupção e Integridade para Empresas de Propriedade Estatal (Guidelines on Anti-Corruption and Integrity in State-Owned Enterprises), publicadas pela OCDE, doravante denominadas ACI Guidelines (OCDE, 2019b).

Ao colocar em perspectiva a Lei das Estatais e as melhores práticas internacionais, abre-se espaço para agendas propositivas, que contemplem a reflexão crítica e (re)construtiva acerca da legislação nacional de promoção da integridade e do compliance, tendo como foco companhias de propriedade estatal.

\footnotetext{
${ }^{1}$ A exemplo dos esquemas de corrupção revelados pela Operação Lava Jato, iniciada em 2014 e considerada a maior operação de combate a corrupção e lavagem de dinheiro da história do Brasil, que além de desvios apurados em contratos com a Petrobras, avançou em diversas frentes, tanto em outros órgãos federais, quanto em contratos irregulares celebrados com governos estaduais (Ministério Público Federal [MPF], 2019).
} 


\section{INTEGRIDADE, COMPLIANCE E ANTICORRUPÇÃO: PERSPECTIVAS}

Centro do debate contemporâneo, as discussões em torno da integridade e do compliance convertem-se em pauta prioritária de empresas e de governos, ganhando, aos poucos, espaço na agenda dos decisores. As discussões sobre o tema avançam na agenda dos conselhos e a função de compliance assume posição estratégica dentro das organizações. Segundo KPMG (2018, p. 4):

Mudanças regulatórias, risco de danos à reputação, multas vultosas aplicadas por órgãos de fiscalização, pressão dos acionistas e stakeholders. Todos esses fatores fizeram com que os executivos passassem a enxergar o compliance como um investimento e não como um custo.

Na prática, no entanto, uma intensa discussão permanece em torno do tema, de seus conceitos e contornos. Há quem compreenda compliance e integridade como sinônimos, e há quem argumente o contrário. Há quem defenda que compliance limita-se à garantia da conformidade ao ambiente regulatório, e há quem pondere, por sua vez, que as fronteiras do compliance são mais amplas, tratando não só da conformidade normativa como também da cultura da ética e da integridade.

Diante da complexidade que envolve o tema, e sem pretender exaurir a questão ou apresentar solução definitiva aos dilemas enunciados, apresenta-se a seguir uma releitura transversal dos temas, discutindo aspectos relevantes para a compreensão das matérias de integridade, compliance e anticorrupção. Afinal, o que significa compliance?

Do ponto de vista literal, a expressão compliance, "[...] se refere a um conjunto de procedimentos adotados por uma determinada sociedade, objetivando otimizar o cumprimento de normas legais, regulamentos e políticas estabelecidos pela organização, com o intuito de mitigar riscos e responsabilidades" (Alves \& Pinheiro, 2017, pp. 43-44), albergando um conjunto de instrumentos estrategicamente modelados sob o formato de um programa, postos em prática para assegurar a completa observância às normas e regulamentos por parte das companhias e de seus representantes.

Sob essa ótica, a concepção de compliance assume caráter destacadamente regulatório, de modo que o termo poderia ser literalmente traduzido por "conformidade", sem prejuízo da compreensão de seu conceito.

Defende-se, aqui, no entanto, que compliance seja compreendido sob uma perspectiva mais ampla, considerando não só os aspectos relacionados à conformidade como também os relativos à cultura da ética, dentro e fora das organizações. Essa cognição ampliada do termo conceitua a função de compliance de maneira mais alargada e estruturante, incorporando ao conceito elementos de ética e integridade, que superam a mera conformidade ao ambiente regulatório.

Segundo Ribeiro e Diniz $(2015$, p. 88) "não se pode confundir o compliance com o mero cumprimento de regras formais e informais, sendo o seu alcance bem mais amplo". Nessa mesma perspectiva, o compliance pode ser considerado

um conjunto de regras, padrões, procedimentos éticos e legais, que, uma vez definido e implantado, será a linha mestra que orientará o comportamento da instituição no mercado em que atua, bem como a atitude dos seus funcionários (Candeloro, Rizzo \& Pinho, 2012, p. 30, como citado em Ribeiro \& Diniz, 2015, p. 88).

Estar em compliance, portanto, "[...] é manter-se em conformidade com as leis e padrões éticos, agindo de maneira preventiva, tentando antecipar condutas reprováveis e criando mecanismos para evitar ações que possam deixar a empresa em desconformidade com o conjunto de normas e preceitos éticos reguladores de sua atividade" (Oliveira, Agapito \& Miranda, 2017, p. 367).

Assim, a concepção de compliance ganha contornos mais flexíveis, passando a englobar "[...] ética, sustentabilidade, cultura corporativa, risco cibernético, gerenciamento de dados e informações de clientes, cadeia de suprimentos, entre outros diversos riscos emergentes" (KPMG, 2018, p. 4). Do ponto de vista prático, a função de compliance adquire novas divisas, debruçando-se não só sobre aspectos relativos à conformidade corporativa, como também sobre questões relacionadas à cultura da ética e da integridade. Surge, então, uma segunda questão: o que é integridade e como ela se relaciona com o compliance?

Segundo Killinger (2010 como citado em Zenkner, 2019, p. 46) “[e]m geral, quando se pensa na palavra integridade, é estabelecida uma relação direta com valores consolidados a partir de conceitos extraídos da ética e da moralidade". Para DeGeorge (1993 como citado em Brown, 2005, pp. 4-5) "[...] acting with integrity is the same as acting ethically or morally". 
Todavia, apesar de intimamente relacionados, os conceitos de ética e integridade não devem ser sinonimizados, visto que ocupam espectros distintos no campo da conduta e do comportamento humanos. Enquanto a ética traz conotações mais filosóficas e intangíveis, a integridade está mais voltada ao comportamento diário dos indivíduos e com o processo de tomada de decisão (Huberts, 2014 como citado em Zenkner, 2019).

Fato é que, tal como o compliance, não há um conceito normativo e definitivo sobre o que seja integridade. O que há é um conjunto de conceitos que, individualmente, contribuem para a compreensão mais substancial do que seja a integridade, não como substituta da ética, mas como um complemento relevante (Brown, 2005). Dentre os vários significados que se podem atribuir ao termo integridade, a noção que advém de sua etimologia é certamente basilar e substancial, servindo como ponto de partida para qualquer análise ulterior.

Derivada do vocábulo integer, que no latim significa integral, ou inteiro, a noção de integridade associa-se à concepção de inteireza, de completude (Zenkner, 2019, p. 47). A noção do inteiro, por sua vez, é indissociável da noção de partes, de forma que só há o todo se existirem as partes que o compõem.

Do ponto de vista individual, uma pessoa íntegra é aquela que não está dividida, ou seja, que está inteira de caráter e realizando suas funções de acordo com os mesmos padrões éticos, independente das circunstâncias (Zenkner, 2019).

Do ponto de vista corporativo, o desafio da integridade está em assegurar a consistência entre os valores organizacionais e as condutas individuais (Brown, 2005), tanto que, para Paine (1994), não é possível dissociar a integridade individual da integridade organizacional:

Many people resist acknowledging the influence of organizational factors on individual behavior especially on misconduct - for fear of diluting people's sense of personal moral responsibility. But this fear is based on a false dichotomy between holding individual transgressors accountable and holding "the system" accountable. Acknowledging the importance of organizational context need not imply exculpating individual wrongdoers. To understand all is not to forgive all (Paine, 1994, p. 109).

No domínio da Administração Pública, por fim, donde atribuições e poderes coletivos são delegados aos servidores públicos, a integridade enquanto baliza moral é inquestionável e esperada (Luijk, 2004, p. 39).

O conceito de integridade adquire, assim, sob o espectro da Administração Pública, contornos específicos, tendo no centro a noção de interesse público. Sobre isso a $\operatorname{OCDE}(2017$, p. 7) discorre da seguinte forma: "[p]ublic integrity refers to the consistent alignment of and adherence to, shared ethical values, principles and norms for upholding and prioritising the public interest over private interests in the public sector".

De igual modo, poder-se-ia argumentar que, da perspectiva da Administração Pública, um dos objetivos centrais do compliance é a prevenção e o combate aos crimes de corrupção, tendo como fim último promover uma melhoria na qualidade de vida da população com a aplicação adequada dos recursos por parte do Estado (Alves \& Pinheiro, 2017).

Para a Controladoria-Geral da União (CGU, 2017), o conceito de integridade pública representa um estado ou condição de inteireza e guia uma atuação imaculada, livre de desvios, e norteada pelo interesse público.

[O] conceito de integridade pública representa um estado ou condição de um órgão ou entidade pública "completo, inteiro, são". Em outras palavras, pode-se dizer que há uma atuação imaculada e sem desvios, conforme os princípios e valores que devem nortear a atuação da Administração Pública (CGU, 2017, p. 5).

Entre a política e o mercado, as companhias estatais ocupam lugar um tanto quanto sui generis, equilibrando aspectos de público e privado. As sociedades de economia mista, em especial, estruturam-se em um arranjo de interesses duais, decorrente da configuração híbrida entre capital público e privado, que produz uma complexidade própria. Tais sociedades constituem desafios à concepção de arranjos de integridade, compliance e anticorrupção que deem conta de suas complexidades e paradoxos. 


\section{AS EMPRESAS ESTATAIS E SEUS PARADOXOS: ENTRE O PÚBLICO E O PRIVADO}

Com longa tradição no desenvolvimento de políticas públicas setoriais, a atuação empresarial do Estado produz efeitos expressivos sobre um vasto número de setores, afetando diretamente indicadores relacionados à vida econômica e social brasileira. O campo de atuação das corporações estatais é amplo, abrangendo funções associadas ao mercado de créditos e capital, ao desenvolvimento de segmentos industriais intensivos em tecnologia e inovação, à matriz energética, à logística, à pesquisa científica e tecnológica, bem como a outros segmentos relevantes para a estratégia nacional (Silva, Schmidt \& Kliass, 2019).

Segundo a Organização para Cooperação e Desenvolvimento Econômico (OCDE, 2019a, p. 14), empresa estatal é "[...] qualquer entidade corporativa reconhecida pela lei nacional como empresa, e na qual o estado exerça propriedade ou controle" ${ }^{2}$, incluindo-se organizações estatutárias estruturadas por leis específicas e cujas atividades sejam de natureza predominanetemente econômica.

No Brasil, a terminologia empresa estatal é empregada como gênero conceitual, subdividindo-se em três espécies: empresas públicas, sociedades de economia mista, e outras sociedades controladas pelo Estado.

O termo Empresas Estatais inclui no direito brasileiro três espécies de entidades, quais sejam, as empresas públicas, as sociedades de economia mista, bem como aquelas demais sociedades existentes e controladas pela iniciativa privada que vieram a ser adquiridas pelo Poder Público sem autorização legislativa específica ou sem observar os procedimentos aplicáveis às empresas públicas ou sociedades de economia mista (Schirato, 2005, p. 210).

Na prática, o ordenamento jurídico nacional particiona a categoria empresa estatal em duas subcategorias principais empresa pública e sociedade de economia mista -, além das subsidiárias, atribuindo a cada uma delas particularidades jurídico-institucionais distintas, assim definidas pelo Decreto no 8.945 (2016):

Quadro 1

Definições de empresa estatal conforme Decreto Federal no 8.945 (2016)

\begin{tabular}{|c|c|}
\hline \multicolumn{2}{|c|}{ Decreto no 8.945 (2016) - Regulamenta a Lei de Responsabilidade das Estatais } \\
\hline \multirow{3}{*}{$\begin{array}{l}\text { Empresa Estatal: } \\
\text { entidade dotada de personalidade jurídica } \\
\text { de direito privado, cuja maioria do capital } \\
\text { votante pertença direta ou indiretamente } \\
\text { à União. }\end{array}$} & $\begin{array}{l}\text { Empresa Pública: empresa estatal cuja maioria do capital votante pertença } \\
\text { diretamente à União e cujo capital social seja constituído de recursos provenientes } \\
\text { exclusivamente do setor público. }\end{array}$ \\
\hline & $\begin{array}{l}\text { Sociedade de Economia Mista: empresa estatal cuja maioria das ações com direito } \\
\text { a voto pertença diretamente à União e cujo capital social admite a participação } \\
\text { do setor privado. }\end{array}$ \\
\hline & $\begin{array}{l}\text { Subsidiária: empresa estatal cuja maioria das ações com direito a voto pertença } \\
\text { direta ou indiretamente a empresa pública ou a sociedade de economia mista. }\end{array}$ \\
\hline
\end{tabular}

Fonte: Elaborado pelos autores com base no Decreto no 8.945 (2016).

Nota-se, pois, com base nas definições estabelecidas no decreto presidencial, que o conceito de empresa estatal, enquanto gênero, é mais amplo, isto é, basta tratar-se de entidade da Administração Pública dotada de personalidade jurídica de direito privado com maioria do capital votante de propriedade do Estado.

Espécies do gênero empresa estatal, tanto as empresas públicas como as sociedades de economia mista possuem personalidade jurídica de direito privado, distinguindo-se quanto à composição e participação do Estado em seu capital social. As empresas públicas caracterizam-se pela constituição do capital por recursos exclusivamente oriundos do setor público, devendo ainda o capital votante pertencer diretamente ao ente federado controlador. A composição societária das sociedades de economia mista, por seu turno, admite a participação privada no capital social, com a restrição de que a maioria das ações com direito a voto pertençam ao Estado (Decreto no 8.945, 2016).

\footnotetext{
"[A]ny corporate entity recognised by national law as an enterprise, and in which the state exercises ownership or control" (OCDE, 2019a, p. 14).
} 
As subsidiárias, por sua vez, resultam do desdobramento da estrutura societária das empresas públicas e sociedades de economia mista em pessoas jurídicas indiretamente controladas pelo Estado, conceituando-se como empresas "[...] cuja maioria das ações com direito a voto pertença direta ou indiretamente a empresa pública ou a sociedade de economia mista" (Decreto no 8.945, 2016).

Seja qual for a espécie da estatal, o debate acerca de suas funções ainda não é pacífico e traz a discussão sobre o papel do Estado na economia. Na visão de Mello (2002), as sociedades de economia mista, as empresas públicas e outras espécies de entes engendrados no plano legislativo pelo Estado configuram formas subjetivas diversas que podem implementar as estratégias assumidas como de interesse público. Sob esse prisma, a empresa estatal pode ser compreendida como um modelo jurídico singular, idealizado e utilizado pelo Estado na realização de atividades e objetivos específicos em que a técnica empresarial e suas virtudes parecem revelar-se instrumentos úteis e necessários (Pinto, 2010).

Na prática, a discussão quanto ao regime jurídico das empresas estatais deriva-se, em grande medida, da dicotomia serviço público versus atividade econômica, baliza teórica para a edificação do regime próprio das empresas de propriedade estatal (Coutinho et al., 2019). A dualidade entre o Estado e o mercado, entre interesses públicos e privados produz efeitos diretos no modelo de governança corporativa das empresas estatais, introduzindo desafios próprios, e um tanto quanto singulares, à concepção de arranjos eficazes de integridade, compliance e anticorrupção.

Ao contrário do grupo controlador da empresa privada, o ente governamental detentor da propriedade não tem, necessariamente, na maximização do resultado o seu objetivo central, o que abre espaço para disputas entre os distintos grupos e coalizões de poder presentes em torno dos objetivos e estratégias a serem perseguidos pela companhia. Nesse contexto, torna-se menor a preocupação com minoritários e investidores, dada a capacidade do Estado em capitalizar a empresa (Fontes-Filho, 2018).

Enquanto nas empresas privadas o acionista ocupa uma posição central no mapa dos stakeholders; nas empresas de propriedade estatal, o conjunto de interesses com potencial para deslocar a ação e a estratégia das companhias é muito mais amplo. Desse modo, qualquer que seja o modelo de integridade, compliance e anticorrupção adotado, deve ser capaz de lidar com expectativas e influências difíceis de conciliar pertencentes a um conjunto mais amplo de atores, que avaliam os resultados de maneira distinta (Fontes-Filho, 2018).

Por um lado, as companhias estatais podem ser objeto de interferência indevida e de motivação política pelo proprietário, produzindo linhas não muito claras de prestação de contas, falta de responsabilização e perda de eficiência nas operações corporativas. Por outro lado, a falta de fiscalização, devido à titularidade passiva ou distante do Estado, pode enfraquecer os incentivos para que as companhias estatais e seus empregados trabalhem no melhor interesse da empresa e do público em geral, que constituem, em última instância, seus acionistas finais (OCDE, 2015).

Conforme destaca Yeung (2005, como citado em Fontes-Filho, 2018), a governança da empresa estatal está sujeita a influências do Estado, do mercado e da sociedade civil - todas muito distintas em termos de fontes de poder, valores, racionalidades e normas -, fato potencialmente gerador de conflitos nas orientações da companhia e de riscos para a integridade e compliance.

No Brasil, a edição da Lei das Estatais canaliza esforços para o aprimoramento dos sistemas de integridade, compliance e anticorrupção das empresas públicas e sociedades de economia mista, convertendo princípios, diretrizes e melhores práticas em lei.

\section{A LEI DAS ESTATAIS E AS ACI GUIDELINES: NORMAS E BOAS PRÁTICAS EM INTEGRIDADE, COMPLIANCE E ANTICORRUPÇÃO}

\section{A Lei das Estatais}

Concebida para regulamentar o art. 173, §1ㅇ da Constituição da República Federativa do Brasil de 1988, a Lei no 13.303 (2016) Lei das Estatais ou Lei de Responsabilidade das Estatais - dispõe sobre o estatuto jurídico da empresa pública, da sociedade de economia mista e de suas subsidiárias.

Inspirada pelos ares de renovação nacional e pela bandeira de prevenção e combate à corrupção, sobressai na Lei das Estatais a preocupação com a governança e a integridade corporativa, impulsionando a adoção de práticas de transparência, compliance, gestão de riscos e controles internos. Tais regras e diretrizes são essenciais “[...] para guiar, daqui para frente, 
a estruturação e a atuação das empresas estatais, mitigando tanto quanto possível as possibilidades de desvio e garantindo um ambiente minimamente seguro para o desenvolvimento de seus negócios e para a prestação de serviços" (Fortini \& Sherman, 2016, p. 175).

Organizada em torno de dois grandes títulos, a Lei das Estatais estabelece o que se poderia denominar regime de governança corporativa das companhias estatais, introduzindo normas e diretrizes específicas de integridade, compliance e anticorrupção, aplicáveis às empresas públicas, sociedades de economia mista e suas subsidiárias. De espectro bastante amplo, o regramento de integridade e anticorrupção - majoritariamente contido no Título I da respectiva lei - possui diretrizes que contemplam desde a obrigatoriedade de elaboração e divulgação de código de conduta e integridade, até a estruturação de unidade específica dedicada à gestão de riscos e ao compliance.

Do ponto de vista de sua extensão, submetem-se ao regime da Lei de Responsabilidade das Estatais toda e qualquer empresa pública e sociedade de economia mista da União, dos Estados, do Distrito Federal e dos Municípios que explorem atividade econômica de produção ou comercialização de bens ou de prestação de serviços, ainda que a atividade econômica esteja sujeita ao regime de monopólio da União (Lei no 13.303, 2016). Submetem-se, ainda, ao regime da lei as sociedades de propósito específico, que sejam controladas pelas empresas públicas ou sociedades de economia mista supramencionadas.

A despeito de dispor de sua aplicação genérica a todo o universo de empresas mencionadas no excerto anterior, a própria lei estabelece exceções explícitas, direcionando a aplicação de seus dispositivos às realidades específicas dos diferentes grupos de companhias estatais. Dentre as exceções estabelecidas pela própria norma, destaca-se o regime de governança corporativa de que trata o Título I, cuja aplicação integral não é imediata a todas as empresas públicas e sociedades de economias mistas.

\section{As diretrizes em integridade e anticorrupção da OCDE}

Publicadas em 2019, as ACl Guidelines foram desenvolvidas pelo Grupo de Trabalho de Propriedade Estatal e Técnicas de Privatização da OCDE em cooperação com outros grupos e unidades internas da organização multilateral, tendo se beneficiado de contribuições recebidas de corporações empresariais, representações sindicais, sociedade civil, países parceiros e outros stakeholders relevantes (OCDE, 2019b).

Resultado de um consenso internacional, as ACl Guidelines são largamente inspiradas nos Princípios para Prevenção da Corrupção e Promoção da Integridade em Negócios Estatais, endossados pelos líderes do Grupo dos 20 (G20) em 2018. Na prática, constitui o primeiro instrumento internacional a oferecer aos Estados proprietários suporte na promoção da integridade e na luta contra a corrupção no espectro das companhias estatais (OCDE, 2019b).

Organizadas em torno de 4 (quatro) dimensões ou grupo de diretrizes, as ACl Guidelines estabelecem recomendações que abrangem desde a promoção da integridade no âmbito do próprio ente controlador, até a promoção da integridade e prevenção à corrupção no nível da companhia estatal. A Figura 1 apresenta as quatro dimensões em torno das quais se organizam as diretrizes estabelecidas pelo documento.

Figura 1

Dimensões (grupo de diretrizes) das ACl Guidelines - 2019

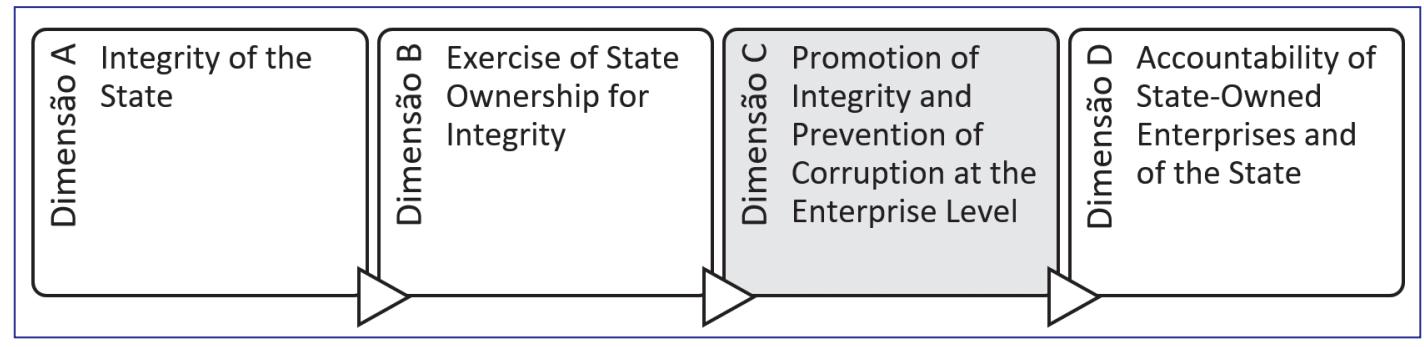

Fonte: Elaborada pelos autores.

${ }^{3}$ G20 High-Level Principles on Preventing Corruption and Ensuring Integrity in State-Owned Enterprises. 
Das quatro dimensões mencionadas, o grupo de diretrizes da Dimensão C é aquele que trata diretamente das medidas de integridade, compliance e anticorrupção no âmbito interno das companhias estatais, recorte a que se dedica este trabalho, conforme detalhado nos procedimentos metodológicos.

A Dimensão C, por sua vez, estratifica-se em 32 recomendações específicas, organizadas em torno de três grandes eixos temáticos, quais sejam: i. gestão integrada de riscos; ii. promoção de controles internos, ética e medidas de compliance; e iii. autonomia das estatais e de seus órgãos decisores. Cada eixo é composto por um conjunto de diretrizes objetivas, que contemplam mecanismos, instrumentos, estruturas e medidas a serem adotados pela empresa pública e sociedade de economia mista como meio para a promoção da integridade e prevenção à corrupção.

Se implementadas, as diretrizes contidas na Dimensão C propiciam a estruturação de um ambiente organizacional mais seguro e menos permissivo a quebras de integridade ou práticas de ato de corrupção, preservando a companhia estatal e o capital público e privado nela investidos.

\section{METODOLOGIA}

Conforme destacam Cooper e Schindler (2003), no campo da Administração as pesquisas devem ser realizadas por meio de investigação sistemática, balizada em critérios consistentes, a fim de gerar informações confiáveis que contribuam para a compreensão dos fenômenos relacionados às organizações e suas instituições.

A presente discussão, de natureza descritiva, investiga os fenômenos organizacionais - no caso, in situ - relacionados a governança corporativa, integridade e anticorrupção nas companhias de propriedade estatal. Na condição de pesquisa bibliográfica e documental, o referencial teórico apresentado nas seções anteriores dá solidez à análise empreendida, cujas principais fontes são a Lei de Responsabilidade das Estatais e as ACl Guidelines.

Para a consecução dos objetivos propostos, a técnica adotada envolve a análise comparativa entre o sistema de integridade, compliance e anticorrupção introduzido pela Lei de Responsabilidade das Estatais e as diretrizes contidas nas ACl Guidelines. Noutros termos, a análise empreendida sustenta-se no estudo da aderência do sistema de integridade e anticorrupção introduzido pela Lei das Estatais às melhores práticas propostas pela OCDE, com ênfase na promoção da integridade e prevenção à corrupção em nível de empresa estatal.

Conforme apresentado no referencial teórico, as ACl Guidelines estruturam-se em torno de 4 (quatro) dimensões ou grupos de diretrizes, cada qual composta por um conjunto de itens e subitens que constituirão os insumos da análise comparativa a ser desenvolvida. Dentre as quatro dimensões em torno das quais se organizam as ACl Guidelines, a análise desenvolvida neste artigo limita-se à denominada Dimensão $\mathrm{C}$, cujo enfoque é direcionado às ações de promoção da integridade e prevenção à corrupção no nível interno das empresas estatais, recorte relacionado à Lei de Responsabilidade das Estatais, que trata do arranjo interno de governança e integridade aplicável às empresas de propriedade do Estado.

Desse modo, a metodologia utilizada se concentrará na análise comparativa entre as diretrizes contidas nos itens da Dimensão C das ACl Guidelines - denominadas ACl Guidelines-Dimensão C - e os dispositivos da Lei de Responsabilidade das Estatais. Para cada item analisado, serão atribuídas as seguintes categorias: aderente, parcialmente aderente e não aderente. Conforme se abstrai dos próprios termos, a categoria aderente será identificada quando a Lei das Estatais implementar integralmente as diretrizes contidas no item analisado. Será registrada a categoria parcialmente aderente quando a referida lei for aderente à fração das diretrizes contidas no item analisado, mas não a todas elas. Por fim, será registrada a categoria não aderente quando a lei não apresentar qualquer convergência com as diretrizes contidas no item analisado. 


\section{ANÁLISE E RESULTADOS: INTEGRIDADE, COMPLIANCE: ANTICORRUPÇÃO NAS EMPRESAS ESTATAIS - A LEI E O ESTADO DA ARTE}

Em linha com os objetivos propostos e com a metodologia externada, expõem-se, a seguir, a análise comparativa e a discussão dos resultados. O Quadro 2 apresenta de forma sintética o resultado agregado da investigação desenvolvida e das conclusões decorrentes da análise de aderência da Lei das Estatais em relação a cada item das ACI Guidelines.

\section{Quadro 2}

Nível de aderência da lei das estatais às diretrizes contidas nas ACl Guidelines - Dimensão C - Brasil - 2020

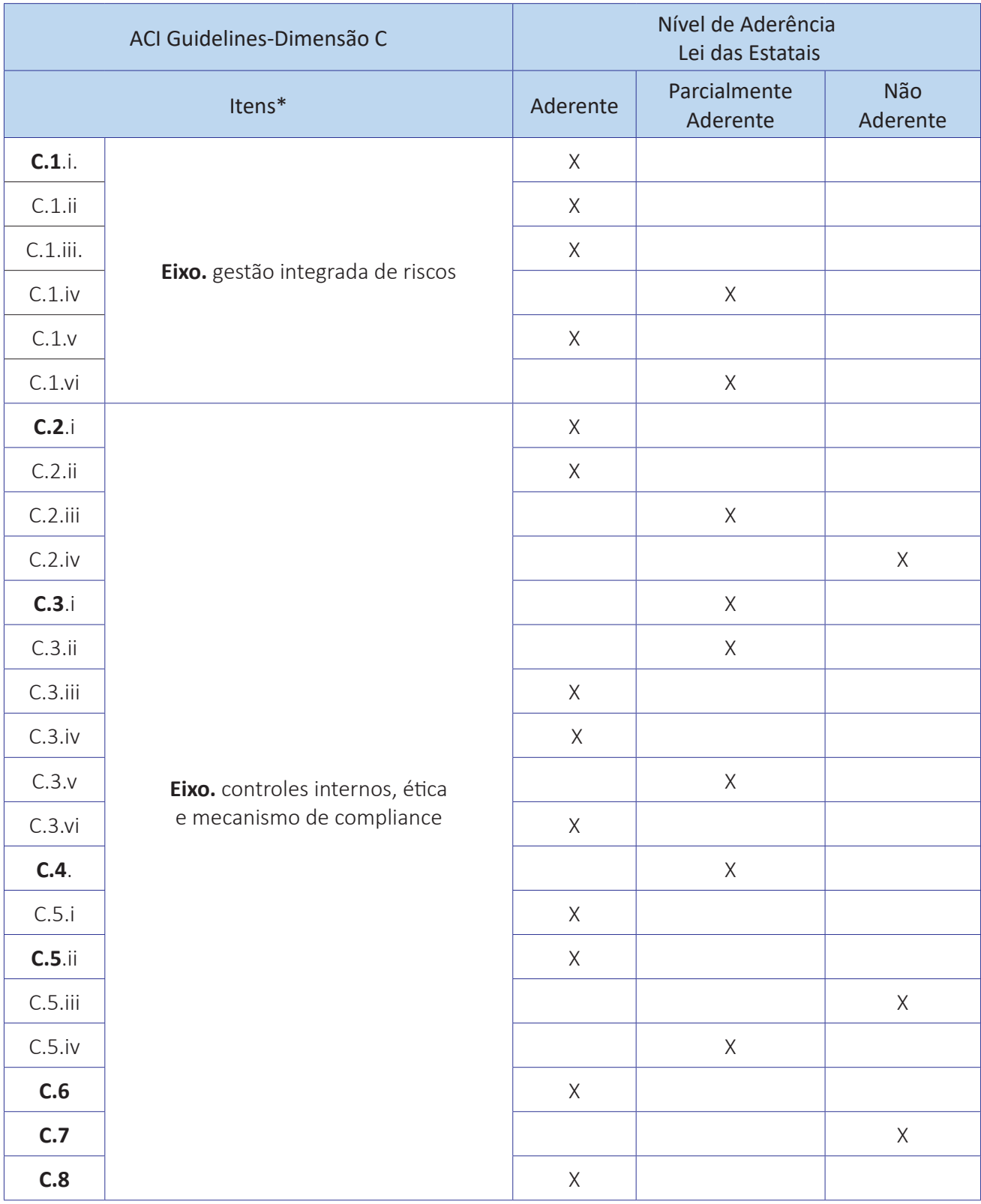

${ }^{4} \mathrm{~A}$ codificação apresentada no Quadro 2 reflete a adotada pelas $\mathrm{ACl}$ Guidelines, de forma que cada código se relaciona a um item específico de análise. Estruturada em três eixos temáticos, a Dimensão C das ACl Guidelines organiza-se em 10 itens e respectivos subitens, cada qual contendo um conjunto de diretrizes e práticas, utilizadas como parâmetro para o estudo desenvolvido. Nesse caso, a análise realizada verificou a aderência da Lei das Estatais a cada um dos itens mencionados. 


\begin{tabular}{|c|c|c|c|c|}
\hline \multirow{2}{*}{\multicolumn{2}{|c|}{$\begin{array}{c}\text { ACI Guidelines-Dimensão C } \\
\text { Itens* }\end{array}$}} & \multicolumn{3}{|c|}{$\begin{array}{l}\text { Nível de Aderência } \\
\text { Lei das Estatais }\end{array}$} \\
\hline & & Aderente & $\begin{array}{c}\text { Parcialmente } \\
\text { Aderente }\end{array}$ & $\begin{array}{c}\text { Não } \\
\text { Aderente }\end{array}$ \\
\hline C.9.i & \multirow{8}{*}{$\begin{array}{l}\text { Eixo. autonomias das estatais } \\
\text { e de seus órgãos decisores }\end{array}$} & & $x$ & \\
\hline C.9.ii & & $x$ & & \\
\hline C.9.iii & & $x$ & & \\
\hline C.9.iv & & $x$ & & \\
\hline C.9.v & & & $x$ & \\
\hline C.9.vi & & & $x$ & \\
\hline C.9.vii & & $x$ & & \\
\hline C.10 & & & $x$ & \\
\hline
\end{tabular}

*Nota: codificação demonstrativa dos itens e subitens da Dimensão $\mathrm{C}$ das $\mathrm{ACl}$ - Guidelines. Fonte: Elaborado pelos autores.

Como se apreende do Quadro 2, a análise do nível de aderência da Lei das Estatais em face do conjunto das diretrizes estabelecidas pela OCDE revela o seguinte cenário: dos 32 itens avaliados, a Lei das Estatais é plenamente aderente a 17 (aproximadamente 53\%), parcialmente aderente a 12 (aproximadamente 38\%) e não aderente a 3 (aproximadamente 9\%).

Se analisado em conjunto, os resultados demonstram certo grau de aderência da Lei das Estatais em relação às diretrizes contidas nas $\mathrm{ACl}$ Guidelines-Dimensão $\mathrm{C}$, de modo que, no que toca à promoção da integridade e prevenção à corrupção no nível interno das companhias estatais, a Lei no 13.303 (2016) contém diretrizes que, uma vez implementadas, estruturam um sistema de integridade e anticorrupção plenamente aderente a mais de $50 \%$ das melhores práticas recomendadas pela OCDE.

No entanto, o grau de aderência parcial também é consideravelmente alto. Em 12 dos 32 itens avaliados, a Lei das Estatais atende parcialmente às diretrizes propostas pela organização multilateral, contemplando pelo menos um dos aspectos centrais da recomendação analisada. Nesses casos, os ajustes necessários à migração para a categoria aderente tendem a ser mais pontuais, uma vez que aperfeiçoamentos menos estruturantes assegurariam a aderência da legislação nacional às diretrizes em questão.

Por fim, em apenas 3 dos 32 itens analisados, não se identificou qualquer convergência entre as melhores práticas e o conteúdo normativo da Lei de Responsabilidade das Estatais. Nesses itens, a Lei das Estatais não apresenta qualquer dos aspectos contidos na recomendação, e a incorporação das diretrizes propostas pela OCDE tende a demandar maiores esforços. O gráfico a seguir ilustra os resultados agregados por eixo temático. 


\section{Gráfico 1}

\section{Percentual de aderência da lei das estatais às $\mathrm{ACl}$ Guidelines - Dimensão C - Por eixo de análise}

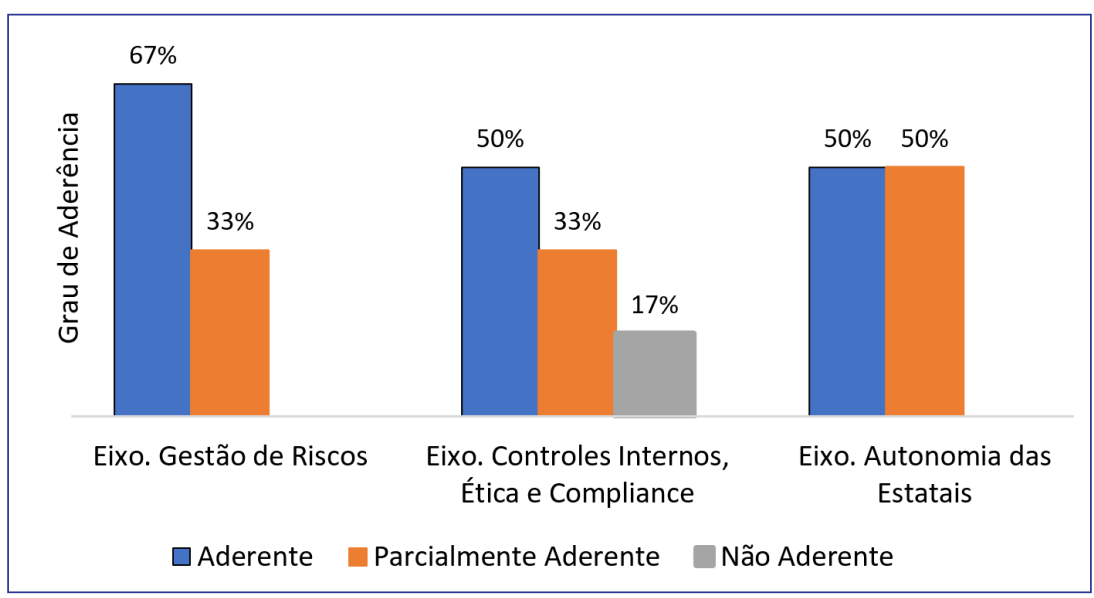

Fonte. Elaborado pelos autores.

Conforme se observa no Gráfico 1, dos três eixos que compõem a Dimensão C das ACl Guidelines, aquele que contempla as diretrizes relativas à promoção de controle interno, ética e compliance é o que dispõe do menor nível de aderência por parte das Lei das Estatais, concentrando, por consequência, maiores oportunidades de avanço. $O$ eixo que contempla as diretrizes relativas à gestão de risco, por seu turno, apresenta o maior nível de aderência à lei, seguido pelo eixo autonomia das estatais e seus órgãos decisores, cuja metade das recomendações encontra correspondência no ordenamento nacional em análise.

Não obstante, como se observa no Quadro 2 e no Gráfico 1, tanto o eixo gestão de riscos como o eixo autonomia das estatais não possuem qualquer item classificado como não aderente. Ratificam, assim, os esforços da Lei das Estatais, de um lado, por estabelecer diretrizes com foco na gestão mais ampla de riscos, que incorpore riscos de integridade, fraude e corrupção, e, de outro, por limitar as oportunidades de influências políticas indevidas na condução da companhia, apostando na qualificação do processo de indicação para o Conselho de Administração, Diretoria Executiva e principais órgãos colegiados, que passam obrigatoriamente a observar requisitos e restrições objetivas.

A estruturação do ambiente de controle interno em torno de três linhas de defesa e a integração da gestão de riscos à estratégia corporativa contribuíram para o fortalecimento do sistema de integridade e compliance, com efeitos diretos na preservação da organização em face dos riscos de fraude e corrupção.

A lei produziu, ainda, um considerável alargamento da autonomia dos órgãos de gestão e governança das empresas estatais em face do Estado proprietário, contribuindo para a mitigação de interferências políticas indevidas na companhia. Para tanto, vetou explicitamente ingerências no exercício da supervisão ministerial, bem como estabeleceu requisitos específicos de qualificação e experiência profissional para a indicação dos administradores, reduzindo o horizonte de nomeações meramente políticas, prática inoportuna sob pelo menos duas dimensões: i. anula o profissionalismo da gestão, trazendo ônus para os resultados empresariais; ii. permite margens para conflitos de interesses potencialmente desdobráveis em fisiologismo na companhia.

Nesse espectro, no entanto, apesar de ser abundante em estabelecer critérios e vedações para a indicação de administradores e membros de órgãos diretivos, a análise revela que ainda há espaço para avançar nos critérios de composição do Conselho de Administração e demais órgãos colegiados, traçando requisitos particulares para posições específicas em cada órgão, com regulamentação direcionada, por exemplo, à posição de presidente do conselho (chairman).

Em relação às recomendações relacionadas à dimensão promoção de controles internos e mecanismos de ética e compliance, a lei demonstra-se bastante consistente em estabelecer as bases corporativas para o desenvolvimento de mecanismos sólidos de integridade e anticorrupção, instituindo área específica responsável pela gestão de riscos e compliance e estruturando o sistema de controles internos em três linhas de defesa. A lei também alinha-se às melhores práticas recomendadas pela OCDE, ao estabelecer política específica de proibição à corrupção, além de introduzir a obrigatoriedade de treinamentos periódicos em código de conduta, integridade e gestão de riscos - tanto para empregados quanto para a alta administração - e imputar 
diretamente ao Conselho de Administração a responsabilidade por discutir, implementar e supervisionar o código de conduta e os sistemas de gestão de riscos e controles internos da companhia.

A lei, entretanto, ainda é acanhada em estabelecer as bases necessárias para o fomento a uma cultura aberta, capaz de estimular os empregados e administradores a trazer à tona situações controversas e potencialmente conflituosas em uma lógica corriqueira. Falha, assim, em estimular um ambiente institucional permeável à dúvida e preparado para lidar preventivamente com potenciais conflitos de interesses, aspectos essenciais à segurança psicológica, indispensável no fomento à cultura de integridade.

Não obstante, apesar de estabelecer recomendações claras quanto ao código de conduta, a lei não contempla, no rol de temas a serem tratados pelo respectivo documento, questões sensíveis como hospitalidade, entretenimento e brindes, doações e caridade, e patrocínio. Tais temas constituem matérias importantes e sensíveis à integridade corporativa, de modo que o esclarecimento das vedações e/ou regras admitidas pela companhia para cada uma das questões é relevante para a prevenção de fraudes e corrupção.

No mesmo sentido, a despeito de introduzir avanços substanciais na seleção e indicação de administradores, a lei é silente em estabelecer parâmetros específicos de integridade para a seleção de empregados não administradores. Nota-se, ainda, espaço para avançar na fixação de parâmetros para regras que expandam a aplicação das medidas e políticas de integridade e anticorrupção para fora dos limites formais da organização, considerando todo o ambiente organizacional em que a companhia está inserida, seus principais stakeholders e parceiros de negócios.

Tal panorama revela avanços já consolidados pela Lei das Estatais e traz reflexões quanto aos horizontes ainda a serem explorados, seja mediante aprimoramento da própria lei e/ou edição de regulamentações complementares.

\section{CONSIDERAÇÕES FINAIS}

Com base no estudo de aderência realizado, observa-se que a Lei de Responsabilidade das Estatais introduziu avanços importantes em integridade e compliance no âmbito interno das empresas estatais, com destaque para o fortalecimento da gestão de riscos e da autonomia das companhias e de seus órgãos decisores.

Os resultados apontam que a Lei das Estatais introduz um sistema de integridade, compliance e anticorrupção relativamente aderente às melhores práticas internacionais que, embora incompleto, parece caminhar em direção ao que se poderia considerar o "estado da arte". Em outras palavras, conclui-se que a Lei de Responsabilidade das Estatais consolida contribuições relevantes para o amadurecimento do ambiente de integridade e anticorrupção das empresas de propriedade estatal no Brasil, introduzindo no ordenamento jurídico nacional um conjunto de regras e diretrizes convergentes às práticas estabelecidas pela OCDE.

Não obstante, as limitações e omissões identificadas sinalizam para a necessidade de uma agenda propositiva de estudos, com foco na investigação e formulação de soluções que deem conta das deficiências detectadas, de modo a contribuir para o aperfeiçoamento da Lei das Estatais e do ambiente institucional de fomento à integridade corporativa e prevenção à corrupção no Brasil.

Reconhecendo as limitações deste estudo - cujo foco se restringe a análise regulatória -, a considerável aderência da Lei das Estatais às melhores práticas internacionais revela que o país caminha na direção correta, de forma que o esforço mais imediato talvez deva se concentrar na implementação adequada e efetiva da legislação disponível. Tal constatação aponta em direção a uma agenda de pesquisas aplicadas - que extrapole a dimensão regulatória deste estudo -, voltada a investigar e compreender os desafios da implementação da lei e seus resultados concretos no universo das companhias estatais. 


\section{REFERÊNCIAS}

Alves, A. F. A., \& Pinheiro, C. R. (2017). O papel da CVM e da B3 na implementação e delimitação do programa de integridade (compliance) no Brasil. Revista Brasileira de Direito Empresarial, 3(1), 40-60.

Brown. M. T. (2005). Corporate Integrity: Rethinking Organizational Ethics and Leadership. Cambridge, UK: Cambridge University Press.

Confederação Nacional da Indústria. (2018, janeiro). Retratos da sociedade brasileira (RSB 41 - Problemas e Prioridades para 2018). Brasília, DF: Autor. Recuperado de http://www.portaldaindustria. com.br/estatisticas/rsb-41-problemas-e-prioridades-para-2018/

Conselho Administrativo de Defesa Econômica. (2016). Guia programas de compliance: orientações sobre a estruturação e benefícios da adoção de programas de compliance concorrencial. Brasília, DF: Autor. Recuperado de http://antigo.cade.gov.br/acesso-a-informacao/publicacoes-institucionais/ guias_do_Cade/guia-compliance-versao-oficial.pdf

Constituição da República Federativa do Brasil de 1988. (1988). Brasília, DF: Senado Federal. Recuperado de http://www.planalto. gov.br/ccivil_03/constituicao/constituicao.htm

Cooper, D. R., \& Schindler. P. S. (2003). Métodos de pesquisa em Administração (7a ed.). Porto Alegre, RS: Bookman.

Coutinho, D. R., Mesquita, C. F. M, \& Nasser, M. V. N. A. M. (2019). Empresas estatais entre serviços públicos e atividades econômicas. Revista Direito GV, 15(1), 1-23.

Decreto $n$ o 8.945, de 27 de dezembro de 2016. (2016). Regulamenta, no âmbito da União, a Lei no 13.303, de 30 de junho de 2016, que dispõe sobre o estatuto jurídico da empresa pública, da sociedade de economia mista e de suas subsidiárias, no âmbito da União, dos Estados, do Distrito Federal e dos Municípios. Brasília, DF. Recuperado de http://www. planalto.gov.br/ccivil_03/_ato2015-2018/2016/decreto/d8945.htm

Fontes-Filho, J. R. (2018, dezembro). A governança corporativa em empresas estatais brasileiras frente a Lei de Responsabilidade das Estatais (Lei no 13.303/2016). Revista do Serviço Público, 69(esp.), 209-238.

Fortini, C., \& Sherman, A. (2016). Governança corporativa e medidas preventivas contra a corrupção na Administração Pública: um enfoque à luz da Lei no 13.303/2016. Revista de Direito da Administração Pública, 1(2), 173-184.

KPMG. (2018). Pesquisa Maturidade do Compliance no Brasil (3a ed.). Recuperado de https://home.kpmg/br/pt/home/insights/2018/06/ pesquisa-maturidade-do-compliance-no-brasil-3a-edicao.html

Lei no 13.303, de 30 de junho de 2016. (2016). Dispõe sobre o estatuto jurídico da empresa pública, da sociedade de economia mista e de suas subsidiárias, no âmbito da União, dos Estados, do Distrito Federal e dos Municípios. Brasília, DF. Recuperado de http://www.planalto. gov.br/ccivil_03/_ato2015-2018/2016/lei//13303.htm

Lei no 13.334, de 13 de setembro de 2016. (2016). Cria o Programa de Parcerias de Investimentos - PPI; altera a Lei $n$ o 10.683, de 28 de maio de 2003, e dá outras providências. Brasília, DF. Recuperado de http:// www.planalto.gov.br/ccivil_03/_ato2015-2018/2016/lei/l13334.htm

Luijk, H. V. (2004). Integrity in the Private, the Public, and the Corporate Domain. In G. G. Brenkert (Org.), Corporate Integrity \& Accountability (pp. 38-54). New York, NY: Sage Publications.

Mello, C. A. B. (2002). Sociedades mistas, empresas públicas e o regime de direito público. Revista Diálogo Jurídico, 13, 1-10. Recuperado de https://www.feg.unesp.br/Home/PaginasPessoais/rogeriapaula dialogo-juridico-13-abril-maio-2002-celso-antonio-bandeira-mello.pdf

Ministério Público Federal. (2019). Caso Lava Jato. Recuperado de http://www.mpf. mp.br/grandes-casos/lava-jato

Oliveira, J. C., Agapito, L. S., \& Miranda, M. A. (2017). O Modelo de "autorregulação regulada" e a teoria da captura: obstáculos à efetividade no combate à lavagem de dinheiro no brasil. Quaestio luris, 10(1), 365-388.

Organização para a Cooperação e o Desenvolvimento Econômico. (2015). Diretrizes da OCDE sobre Governança Corporativa de Empresas Estatais. Recuperado de https://doi.org/10.1787/978926418 1106-pt

Organização para a Cooperação e o Desenvolvimento Econômico. (2017). Public Integrity: a strategy against corruption. Recuperado de https://www.oecd.org/gov/ethics/OECD-RecommendationPublic-Integrity.pdf

Organização para a Cooperação e o Desenvolvimento Econômico. (2019a). Guidelines on Anti-corruption and Integrity in State-Owned Enterprises. Recuperado de www.oecd.org/corporate/Anti-CorruptionIntegrity-Guidelines-for-SOEs.htm

Organização para a Cooperação e o Desenvolvimento Econômico. (2019b). ACl Guidelines - Info. Recuperado de https://www.oecd. org/corruption/

Paine, L. S. (1994). Managing for Organizational Integrity. Harvard Business Review, 72(2), 106-117.

Pinto, H. M. (2010). A autarquização das empresas estatais na jurisprudência do Supremo Tribunal Federal: um obstáculo para as reformas na Administração Pública. Cadernos Gestão Pública e Cidadania, 15(57), 215-233.

Ribeiro, M. C. P., \& Diniz, P. D. F. (2015). Compliance e Lei Anticorrupção nas Empresas. Revista de Informação Legislativa, 52(205), 87-105.

Schirato, V. R. (2005). Novas anotações sobre as Empresas Estatais. Revista de Direito Administrativo, 239, 209-240.

Silva, M. S., Schmidt, F. H., \& Kliass, P. (2019). Empresas estatais: políticas públicas, governança e desempenho. Brasília, DF: Ipea.

Zenkner, M. (2019). Integridade governamental e empresarial: um espectro da repressão e da prevenção da corrupção no Brasil e em Portugal. Belo Horizonte, MG: Fórum. 
Marcos Caldeira

ORCID: https://orcid.org/0000-0003-2195-7736

Mestre em Administração Pública e Professor da Escola de Governo Professor Paulo Neves de Carvalho da Fundação João Pinheiro (FJP); Especialista em Direito Público; Especialista em Políticas Públicas e Gestão Governamental. E-mail: m_caldeira@outlook.com

Simone Cristina Dufloth

ORCID: https://orcid.org/0000-0002-1963-7365

Doutora em Ciência da Informação pela Universidade Federal de Minas Gerais (UFMG); Professora do Programa de Mestrado em Administração Pública da Escola de Governo Professor Paulo Neves de Carvalho da Fundação João Pinheiro (FJP). E-mail: simone.dufloth@fjp.mg.gov.br 